\title{
MODIFICATION OF THE MECHANICAL PROPERTIES OF RUBBERS BY INTRODUCING RECYCLED RUBBER INTO THE ORIGINAL MIXTURE
}

\author{
CS. VARGA ${ }^{1, *}$ \\ N. MISKOLCZI \\ L. BARTHA ${ }^{1}$ \\ L. PALOTÁS ${ }^{2}$
}

\author{
${ }^{1} \mathrm{MOL}$ Institutional Department of Hydrocarbon \& \\ Coal Processing, Institute of Chemical and Process Engineering, \\ Faculty of Engineering, University of Pannonia, \\ Egyetem u.10. Veszprém H-8200, Hungary \\ ${ }^{2}$ Palotás-Mix Ltd. Kemeneshögyész, \\ H-8516 Hungary
}

Received: $18 / 01 / 10$

Accepted: 02/09/10 *to whom all correspondence should be addressed: e-mail: vcsilla@almos.uni-pannon.hu

\begin{abstract}
In our experimental work the opportunities of improving of mechanical properties of rubbers and their composites have been investigated. On the one hand the reuse of milling product of recycled rubbers (recycled crumb rubbers) has been studied and the effects of the filler and compatibilizers applicable in rubber composites on the mechanical properties either. The rubber composites were exposed to different mechanical stresses (tensile, fatigue tensile) and Shore A hardness and density of the specimens have also been determined. Morphology of the composites and the interaction between the fillers and the rubber has been studied on SEM graphs. Recycled crumb rubber was added in different concentrations to the basic mixture of rubber. Significant improvement of mechanical properties could be achieved by mixing $22 \mathrm{~m} / \mathrm{m} \%$ used crumb rubber to the basic mixture. Tensile strength at break of composites containing recycled crumb rubber increased with nearly $20 \%$ compared to the original basic mixture containing no crumb rubber. Density decreased with $2-3 \%$ and Shore A hardness with $6 \%$ comparing the aforementioned composites. Different types of compatibilizing additives have also been applied in the system containing crumb rubber which showed different effectiveness in case of the properties, e.g. tensile strength at break. Adding compatibilizing additives to the basic mixture of rubber did not make the density changed while Shore A hardness changed similarly to the trend observed in case of tensile strength at break.
\end{abstract}

KEYWORDS: compatibilizing additive, reuse of recycled rubber, rubber composites.

\section{INTRODUCTION}

Billions of tyre rubbers are withdrawing from circulation throughout the world in a year. At about 150 billion pieces of tyres are used, approximately 1650 thousand tons, in Europe a year, from which 4050 thousand tons are expended in Hungary [1]. At about $60 \%$ of rubbers are recycled in different ways in the world and the rest is being dumped. Used tyre rubbers can be recycled in various forms, like entire, split or crumb rubber, etc.

Recycling can be carried out in different ways. The main recycling pathways are the thermal recycling (by burning) and the physical or chemical regenerating by which additives in forms of crumb rubber can be produced for asphalts and polymers [2].

There are several researches for producing compounds originated from crumb rubbers. The mechanical properties of such compounds are bad due to the poor adhesion of the components and the high heterogeneity of the crumb rubber. Various processes can be applied for improving those properties such as adding thermoplastic elastomer to the mixture of thermoplastics and rubbers, or modification of the surface of the crumb rubber with various additives (silanes, different copolymers or bitumens) [3-7].

In our experimental work the opportunities of improving of mechanical properties of SBR rubbers and their composites have been investigated. On the one hand the reuse of milling product of 
recycled rubbers (crumb rubbers) has been studied and on the second hand the effects of filler and compatibilizers applicable in rubber composites on the mechanical properties have been investigated either.

\section{EXPERIMENTAL}

\subsection{Materials}

Recycled ground tyre crumb rubbers have been applied for production of rubber composites with the properties in Table 1.

Table 1. Properties of recycled crumb rubbers

\begin{tabular}{|c|c|c|}
\hline \multicolumn{3}{|l|}{ Particle size distribution, w/w\% } \\
\hline & Crumb rubber 1 (CR1) & Crumb rubber 2 (CR2) \\
\hline $0-0.25 \mathrm{~mm}$ & 64 & 5 \\
\hline $0.25-0.40 \mathrm{~mm}$ & 32 & 7 \\
\hline $0.40-0.63 \mathrm{~mm}$ & 4 & 53 \\
\hline $0.63-1.00 \mathrm{~mm}$ & - & 32 \\
\hline $1.00-1.25 \mathrm{~mm}$ & - & 2 \\
\hline $1.25-1.60 \mathrm{~mm}$ & - & 1 \\
\hline \multicolumn{3}{|l|}{ Composition } \\
\hline & Crumb rubber 1 (CR1) & Crumb rubber 2 (CR2) \\
\hline $\begin{array}{l}\text { adherent moisture content, } \\
\text { w/w\% }\end{array}$ & 0.4 & 0.3 \\
\hline part, soluble in acetone, w/w\% & 8.5 & 11.9 \\
\hline $\begin{array}{l}\text { part, soluble in chloroform, } \\
w / w \%\end{array}$ & 0.3 & 0 \\
\hline$\Sigma$ isoprene content, w/w\% & 58.5 & 52.3 \\
\hline NR+IR content, w/w\% & 36.5 & 27.7 \\
\hline carbon black content, w/w\% & 27.2 & 26.3 \\
\hline ash content, w/w\% & 5.1 & 9.2 \\
\hline compatibility index ${ }^{*}$ & 2.68 & 1.31 \\
\hline \multicolumn{3}{|c|}{$\mathrm{NR}+\mathrm{IR}$ content, w/w\% } \\
\hline
\end{tabular}

The compatibilizers applied in the rubber composites were experimental polyalkenyl-poly(maleicanhydride) based coupling agents produced at our Institutional Department. The major aspects of compositions were summarized in Table 2 . The main differences were in the length and functionality of the amine chains (the number of amine and hydroxyl groups).

\subsection{Processing of composites}

During processing of experimental composites a basic mixture was previously produced without initiator and sulphur. That was used for production of the reference sample (sample number: 0 ) by mixing with initiator and sulphur in the roller mill. The 1 . sample was produced by mixing the basic mixture, the recycled ground rubber the initiator and the sulphur. Two rubber composites were produced by applying six different compatibilizing additives. The samples were vulcanized and sheets were pressed of the mixtures. Dog-bone specimens were cut our of the sheets and were of the size $2 \mathrm{~mm} \times 6,6 \mathrm{~mm} \times 115 \mathrm{~mm}$.

\subsection{Tests}

The rubber composites made by compression moulding were exposed to different mechanical stresses (tensile, fatigue tensile) and Shore A hardness and density of the specimens were also determined. Morphology of the composites and the interaction between the fillers and the rubber was studied on SEM graphs.

The specimens were investigated with both standardized and non-standardized methods. To determine the tensile and fatigue tensile properties (stress and elongation) (MSZ EN ISO 527-14:1999, MSZ EN ISO 14125:1999) an INSTRON 3345 universal tensile testing machine was used. The temperature in the laboratory was $20^{\circ} \mathrm{C}$ and the relative humidity was $50 \%$ during the 
mechanical tests. Tensile tests were carried out at $90 \mathrm{~mm} \mathrm{~min}^{-1}$ crosshead speed. Shore A hardness of rubbers was determined according to the DIN 53505:2000 standard. Fatigue tensile tests were also carried out at $90 \mathrm{~mm} \mathrm{~min}^{-1}$ crosshead speed, the applied fatigue stress was $10 \mathrm{~N}$ during 100 fatigue cycles.

Scanning Electron Microscopy (SEM) was used to study the structure of fractured faces of specimens and to follow possible interaction between the crumb rubber and the rubber matrix. The applied apparatus was a Phillips XL30 ESEM instrument.

Table 2. Types of compatibilizers used

\begin{tabular}{|c|c|c|c|}
\hline Compatibilizer sign & Base polymer chain & Additive type & $\begin{array}{l}\text { Functionality (amine } \\
\text { /hydroxyl groups) }\end{array}$ \\
\hline CA-1 & $\begin{array}{l}\text { maleic-anhydride and } \\
\text { styrene grafted PIB }\end{array}$ & $\begin{array}{l}\text { ester-amide } \\
\text { derivative }\end{array}$ & 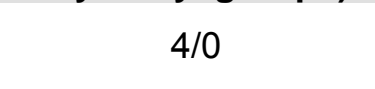 \\
\hline CA-2 & $\begin{array}{l}\text { maleic-anhydride and } \\
\text { styrene grafted PIB }\end{array}$ & $\begin{array}{l}\text { ester-amide } \\
\text { derivative }\end{array}$ & $4 / 0$ \\
\hline CA-3 & $\begin{array}{l}\text { maleic-anhydride and } \\
\text { styrene grafted PIB }\end{array}$ & $\begin{array}{l}\text { ester-amide } \\
\text { derivative }\end{array}$ & $1 / 0$ \\
\hline CA-4 & $\begin{array}{l}\text { maleic-anhydride and } \\
\text { styrene grafted PIB }\end{array}$ & $\begin{array}{l}\text { ester-amide } \\
\text { derivative }\end{array}$ & $1 / 2$ \\
\hline CA-5 & $\begin{array}{c}\text { polyalkenyl-poly(maleic- } \\
\text { anhydride) }\end{array}$ & $\begin{array}{l}\text { ester-amide } \\
\text { derivative }\end{array}$ & $1 / 0$ \\
\hline CA-6 & $\begin{array}{c}\text { polyalkenyl-poly(maleic- } \\
\text { anhydride) }\end{array}$ & $\begin{array}{l}\text { ester-amide } \\
\text { derivative }\end{array}$ & $1 / 2$ \\
\hline
\end{tabular}

\section{RESULTS}

\subsection{Mechanical properties}

Two experimental series of rubbers were produced by adding crumb rubber to the basic rubber mixture. Six different types of additives were applied in the rubber composites. The composition of the samples was summarized in Table 3.

Table 3. Composition of rubber composite samples

\begin{tabular}{|lc|}
\hline Sample composition & Sample number \\
Basic rubber (BR1) & 0 \\
Basic rubber with 22w/w\% crumb rubber content (CR1) & 1 \\
Basic rubber with 22w/w\% crumb rubber content (CR1) \& CA-1 & 2 \\
Basic rubber with 22w/w\% crumb rubber content (CR1) \& CA-2 & 3 \\
Basic rubber with 22w/w\% crumb rubber content (CR1) \& CA-3 & 4 \\
Basic rubber with 22w/w\% crumb rubber content (CR1) \& CA-4 & 5 \\
Basic rubber (BR2) & 6 \\
Basic rubber with 22w/w\% crumb rubber content (CR2) & 7 \\
Basic rubber with 22w/w\% crumb rubber content (CR2) \& CA-5 & 8 \\
Basic rubber with 22w/w\% crumb rubber content (CR2) \& CA-6 & 9 \\
\hline
\end{tabular}

As Figure 1 showed the tensile strength of the rubber decreased to the half by adding $22 \mathrm{w} / \mathrm{w} \%$ recycled crumb rubber (CR1) to the basic mixture (BR1) (see sample "1"). Application of compatibilizing additives (CA-1 to CA-4) showed different effectiveness. CA-2 additive was the most effective, the tensile strength of the rubber composite increased by $18 \%$ (sample " 3 "). The other additives had much slighter effects on the tensile strength. But the tensile strength of the original rubber could not even be achieved by application of the compatibilizers. 


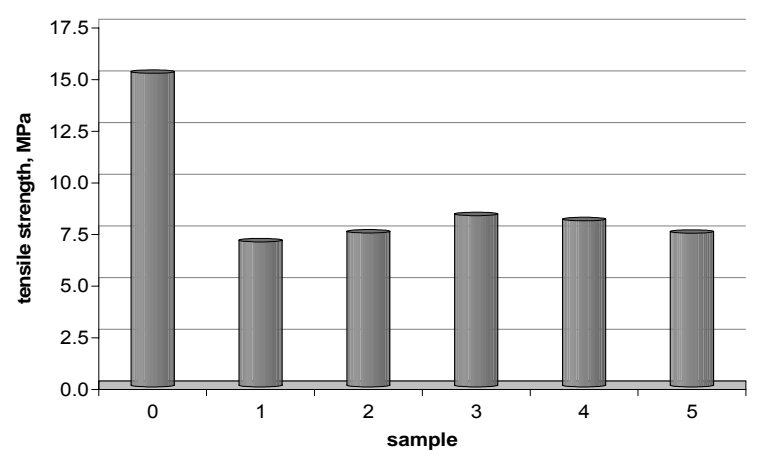

Figure 1. Tensile strength at break of the different rubber composites

Elongations at break decreased either by blending crumb rubbers and different types of compatibilizers to the original rubber. The decreasing ratio was in the range of $10-15 \%$.

The decreasing trends in case of the samples "1-5" could probably be caused by the insufficient rubber particle distribution in the original mixture and as results showed the compatibilizers could not even solve the problem properly.

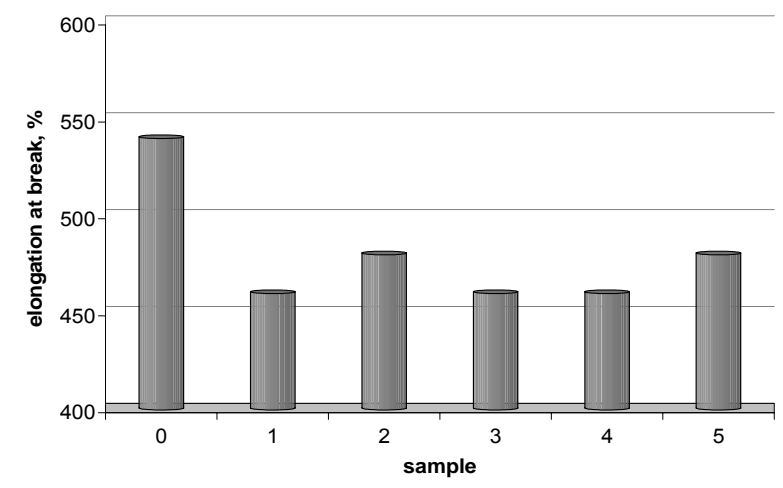

Figure 2. Elongation at break of the different rubber composites.

Recycled crumb rubber of ground tyre (CR2) was added in different concentrations to the basic mixture of rubber. Significant improvement of mechanical properties could be achieved by mixing $22 \mathrm{w} / \mathrm{w} \%$ used ground tyre rubber to the basic mixture. Density decreased with 2-3\% (Figure 3 ) and Shore A hardness decreased with $6 \%$ comparing the aforementioned composites. Different types of compatibilizing additives have also been applied in the system containing crumb rubber and showed different effectiveness in case of the properties, e.g. tensile strength at break. Abrasion property of rubbers changed by $10 \%$ by blending recycled crumb rubber into the raw material but applying compatibilizing additive beside the raw material and the recycled crumb rubber did not make the abrasion property change.

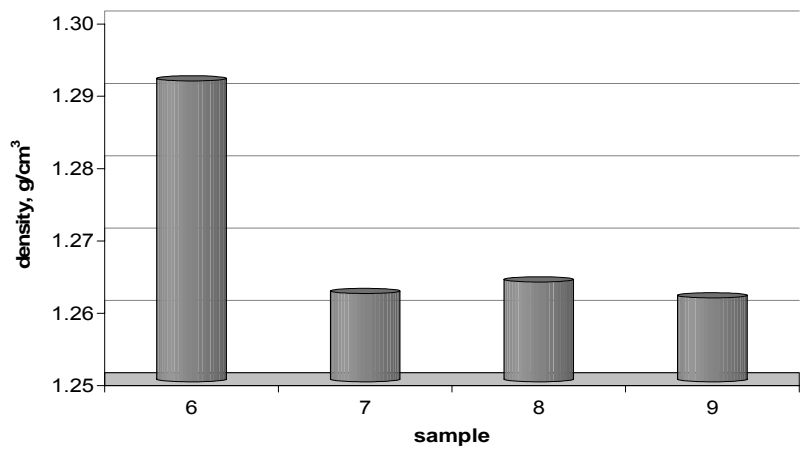

Figure 3. Density of rubbers with different compositions 
Adding crumb rubber to the basic mixture did not make the density increased, moreover the density decreased by a moderate degree. The addition of compatibilizing additive had no effect on the density of the basic rubber containing $22 \mathrm{w} / \mathrm{w} \%$ recycled crumb rubber.

Tensile strength at break of composites containing recycled crumb rubber increased with nearly $20 \%$ compared to the original basic mixture containing no crumb rubber (Figure 4). No significant effects could be observed in tensile strength by applying compatibilizing additive. The additive, CA-5 did not make the tensile strength changed but the CA- 6 additive had significant deteriorating effect. The tensile strength of the rubber with CA-6 additive and crumb rubber was much lower (at about 20\%) than the tensile strength of the basic rubber mixture.

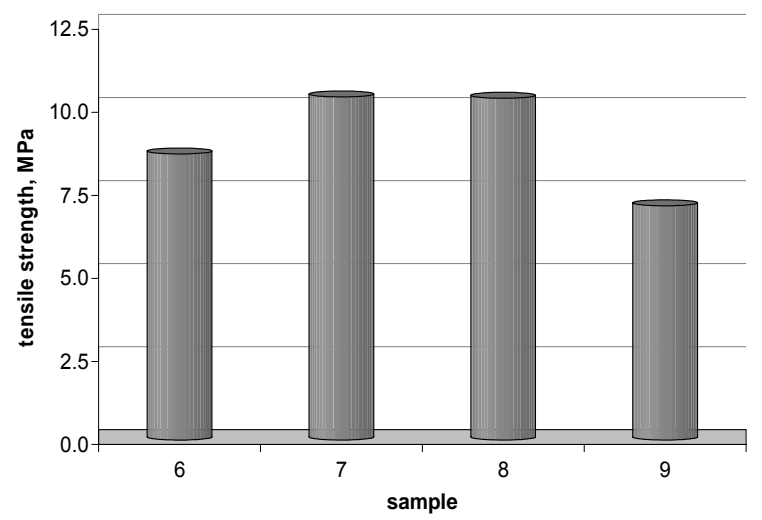

Figure 4. Tensile strength at break of the different rubber composites

Elongations at break (Figure 5) were at about $300 \%$ and increased by $6 \%$ by addition of crumb rubber to the original rubber, so the rubber composites became more elastic. Application of compatibilizers had no effects on that property of the products.

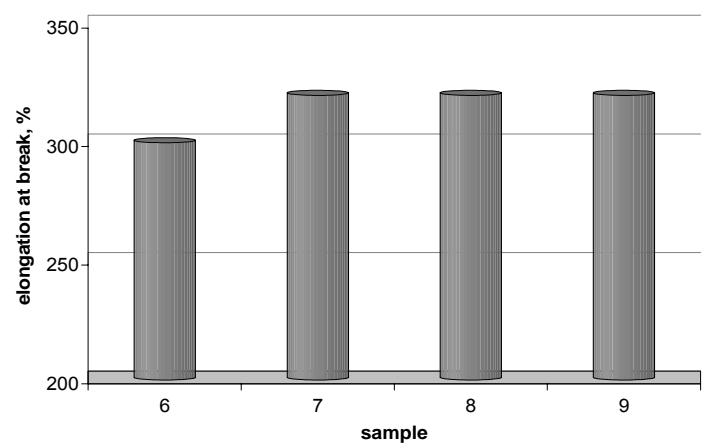

Figure 5. Elongation at break of the different rubber composites

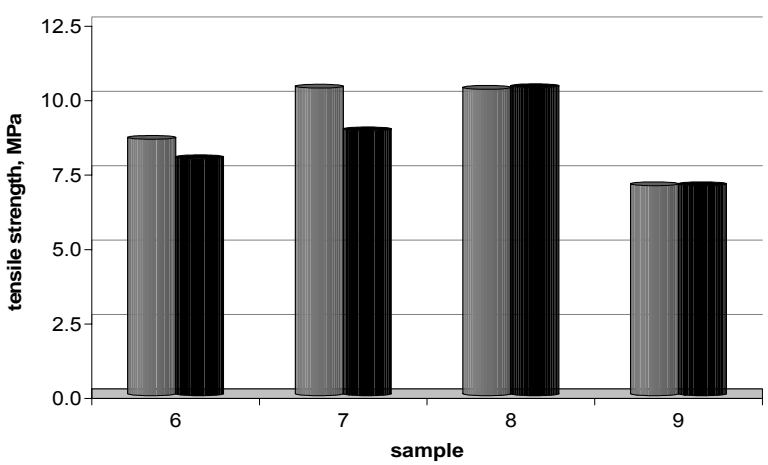

Figure 6. Tensile strength at break of the different rubber composites in case of the different tensile tests 
Fatigue tensile test results showed interesting trends (Figure 6). While the fatigue tensile strength at break of the blend of basic mixture and used crumb rubber decreased with $6 \%$ and $13 \%$, respectively. But the fatigue tensile strength at break of the compatibilized composites did not change with fatigue tensile stresses. Fatigue stresses had significant effects on the elongations at break. Approximately $30 \%$ increase could be observed in case of the recycled crumb rubber containing composites compared to the same properties of the simple tensile tests. Fatigue stress had no effect on the elongation at break of the basic rubber mixture.

\subsection{Scanning Electron Microscopy}

The crumb rubber distribution was investigated of the different broken face of the rubber composite by Scanning Electron Microscopy. The SEM graphs were shown in Figures 7-10.

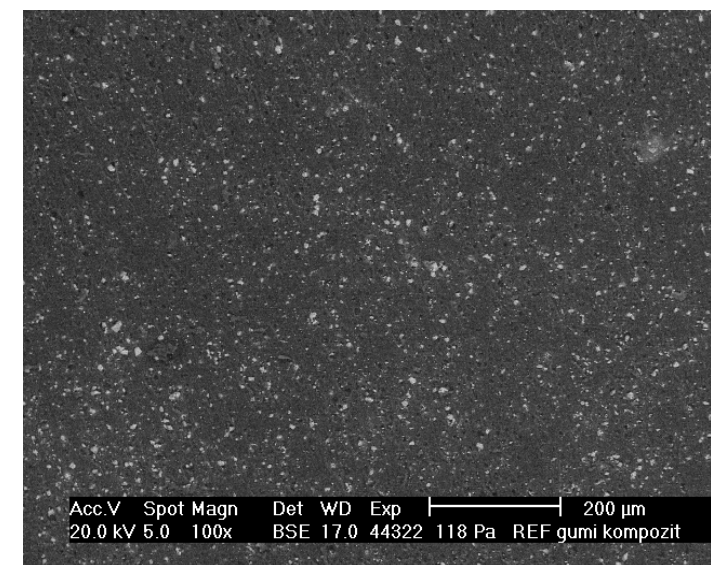

Figure 7. SEM graphs of the broken surface of the original rubber (sample "6")

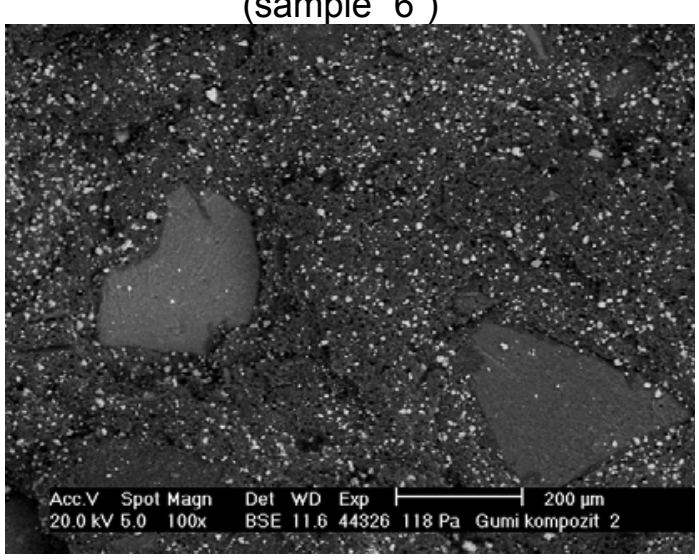

Figure 9. SEM graphs of the broken surface of the original rubber with $22 \mathrm{w} / \mathrm{w} \%$ crumb rubber and CA-5 (sample "8")

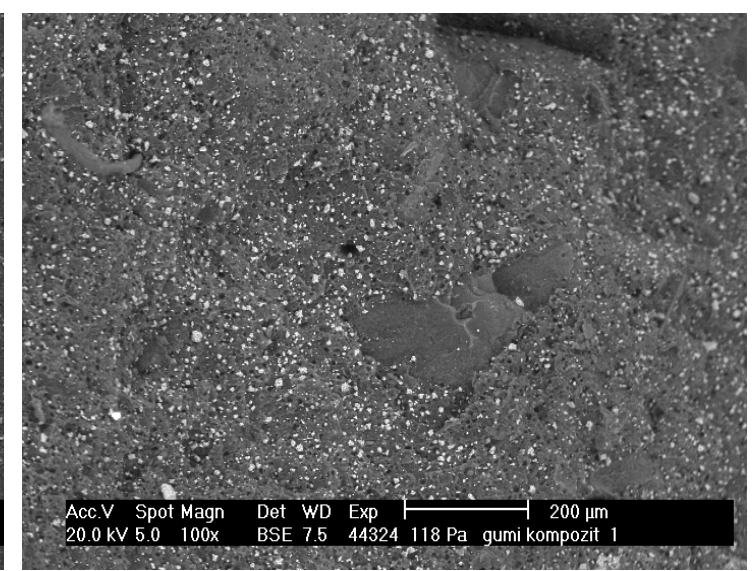

Figure 8. SEM graphs of the broken surface of the original rubber with $22 \mathrm{w} / \mathrm{w} \%$ crumb rubber (sample "7")

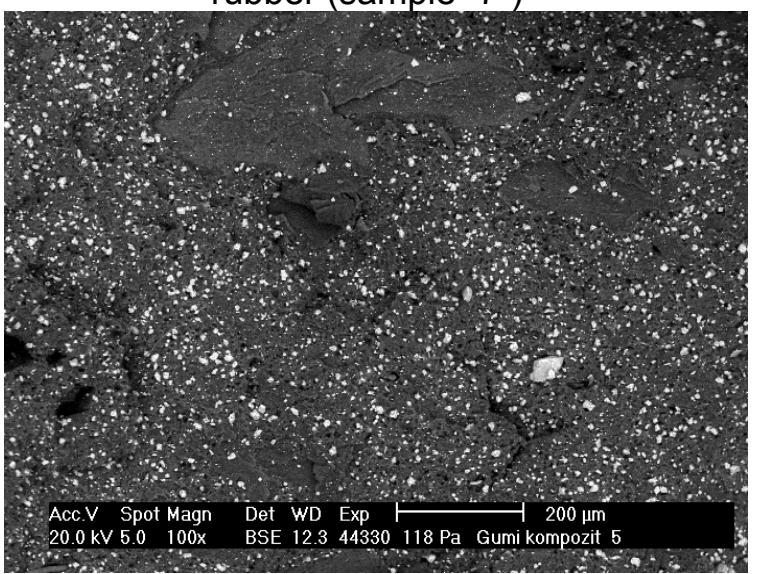

Figure 10. SEM graphs of the broken surface of the original rubber with $22 \mathrm{w} / \mathrm{w} \%$ crumb rubber and CA-6 (sample "9")

Crumb rubber particles can be clearly seen in Figures 8-10. The broken surface of the rubber composites with additives showed differences. The wrong mechanical properties could be caused by the insufficient interaction between the components because there were big holes and gaps on the surface of the CA-6 additive containing sample, "9", but the tensile properties of the sample " 8 " were much better which can be attributed to better interaction inside the composite and the broken surface of the sample was also much more balanced. There was no significant difference between the surfaces of the samples "7" and "8". 


\section{CONCLUSIONS}

The results were summarized as follows:

- The results have proved that the type of the basic rubber and the type of the crumb rubbers and their particle size distributions can significantly influence the mechanical properties of the rubber composites. It was also clearly indicated that the selection of the proper additive can have significant effects on the physical properties of the rubber end products.

- Density of specimens decreased by $2.5 \%$ by mixing recycled crumb rubber, which can result in saving raw materials in case of application at the same value.

- Application of compatibilizing additives in the composites has different effects on the mechanical and physical properties. Comparing the composites containing compatibilizers to the composite system without additive the tensile strength at break changed within the range of repeatability of measurements. So the disadvantage of the composite without additive was only the more difficult processing and the wider range of standard deviation of the parallel measurements. The latter may be caused by the absent of the additive because of the inhomogeneous particle distribution of the end product.

- A higher tensile strength at break could be realized beside increasing maximal tensile elongation and elongation at break. According to the results it was proved that the crumb rubber made the rubber composite more elastic.

- Based on the results by developing a proper process for mixing of the recycled crumb rubbers the ratio of recycling of the rubber raw materials could be increased.

\section{REFERENCES}

1. Matkó Sz., Marosi Gy., Zubonyai F. and Garas S., (2006) Gumi- és műanyaghulladékok értéknövelő újrahasznosítása (Upcycling of rubber and plastic waste), Müanyag és Gumi (Plastics and Rubbers), 43, 308-311.

2. Adhikari B., Maiti D. and De S. (2000), Reclamation and recycling of waste rubber, Prog Polym Sci, 25, 909-948.

3. Grigoryeva O.P., Fainleib A.M., Tolstov A.L., Starostenko O.M., Lievana E. and Karger-Kocsis J. (2005) Thermoplastic elastomers based on recycled high-density polyethylene, ethylene-propylenediene monomer rubber, and ground tire rubber, J Appl Polym Sci, 95, 659-671.

4. Abdelmouleh M., Boufi S., Belgacem M.N. and Dufresne A. (2007) Short natural-fibre reinforced polyethylene and natural rubber composites: Effect of silane coupling agents and fibres loading, Comp Sci Tech, 67, 1627-1639.

5. Asaletha R., Kumaran M.G. and Thomas S. (1999) Thermoplastic elastomers from blends of polystyrene and natural rubber: morphology and mechanical properties Eur Polym Journal, 35, 253271.

6. Rouilly A., Rigal L. and Gilbert G. (2004) Synthesis and properties of composites of starch and chemically modified natural rubber, Polymer, 45, 7813-7820.

7. Ismail H. and Hairunezam H.M., (2001) The effect of a compatibilizer on curing characteristics, mechanical properties and oil resistance of styrene butadiene rubber/epoxidized natural rubber blends, Eur Polym Journal, 37, 39-44. 